\title{
LA RESTAURACIÓN DEL COSMOS SAGRADO EN EL CRISTIANISMO ORTODOXO
}

\author{
Felipe Cárdenas Támara \\ Universidad de La Sabana. Colombia
}

Resumen: El objetivo del artículo es identificar las principales estructuras narrativas en el discurso ambiental que el Patriarca Bartolomé viene desarrollando desde el año de 1989. El concepto de estructura narrativa, específicamente se estudia en relación con la dimensión ambiental.

Palabras clave: Teología ortodoxa, crisis ambiental, Patriarca Bartolomé, narrativa, cristianismo ortodoxo.

\section{THE RESTAURATION OF THE SACRED COSMOS IN ORTHODOX CHRISTIANITY}

\begin{abstract}
The aim of the article is to identify the principal narrative structures in the discourse that Patriarch Bartholomew is developing since the year 1989. The concept of narrative structure, specifically is studied in relation to the environmental dimension.
\end{abstract}

Keywords: Orthodox theology, environmental crisis, Patriarch Bartholomew, narrative, Orthodox Christianity.

Recibido:5.05.2017 Aceptado: 4.07.2017

Correspondencia: Felipe Cárdenas Támara

Email: felipe.cardenas@unisabana.edu.co

Dr. en Antropología, Magna cum Laudem en Antropología, Bircham International University. Magister en Desarrollo Rural, PUJ; Antropólogo, Universidad de los Andes. Colombia. Profesor Asociado Universidad de La Sabana. Homeópata titulado, British Institute of Homeopathy Director del grupo de investigación Sociopolítica, cultura y ambiente. Director de la maestría en Educación de la Universidad de La Sabana.

El autor agradece las correcciones de estilo de la psicóloga Camila Cárdenas Cuéllar, graduada de la Universidad de La Sabana. 


\section{Introducción}

Las llamadas estructuras narrativas, desde el anclaje interdisciplinar señalado en la primera parte de este trabajo de investigación, establecen complejas relaciones comprensivas con las lógicas de la vida y con las cadenas de significación que las diversas culturas le han otorgado a la dimensión ambiental y territorial. En efecto, el análisis narratológico o discursivo de los materiales que se analizan está relacionado con una riquísima inter-textualidad, que se nutre de los desarrollos conceptuales y/o espirituales de la tradición teológica bizantina y de todo el rango de desarrollos teológicos sujetos a las tradiciones de las llamadas iglesias de oriente, incluidas las iglesias no-calcedónicas.

Las concepciones de mundo, cuya base es de orden narrativo y discursivo, se plasman en prácticas socioculturales, que en su devenir histórico, son dimensiones esenciales a las estructuras narrativas de toda tradición cultural. Consecuentemente, el ambiente del ser humano está culturalmente constituido, y en la interacción sociedad-ecosistema, la denominada naturaleza es a su vez un artefacto cultural, que en el caso de la relación ambiental está sujeto a las variaciones ontológicas, históricas y culturales. Desde dicho horizonte, debe tenerse en cuenta cómo un mensaje, por ejemplo el que genera un relato, tómese la narración del libro del Génesis 1:28, estará mediado por diversas interpretaciones sincrónicas y diacrónicas, que hacen que el proceso interpretativo pueda ser entendido como una empresa apta para indagaciones científicas, que tienen que apoyarse en la hermenéutica, teología, arqueología, semiótica, antropología cultural, geografía e historia de las religiones. De ahí que la interpretación de todo texto, relato, narración, discurso o mito, tenga que tener en cuenta en su proceso de análisis semiótico, una serie de considerandos. Por ejemplo, para el caso de los relatos bíblicos el análisis debe realizarse, teniendo en cuenta como mínimo lo siguiente: i) identificar en lo posible el significado dado por quien lo escribió, y quien no necesariamente tenía a su disposición todos los elementos históricos y culturales, que actualmente tiene un exegeta, para comprender dimensiones relaciones del mensaje escrito; ii) igualmente el texto en mención es interpretado de manera diferencial por las distintas corrientes de interpretación bíblica que buscan establecer el verdadero significado del texto, ya sea en una lectura espiritual alegórica o en una lectura crítico-histórica 


\section{Expresión relacional de las principales estructuras narrativas.}

El campo referencial del discurso analizado y como expresión del sistema de producción discursivo del Patriarca Bartolomé, está en referencia al fenómeno de la crisis y problemática ambiental, que se comprende con base en los anclajes proporcionados por la experiencia de orden de la teología bizantina. El significado de la crisis ambiental es profundo, como profundo es el despliegue semiótico producido en los textos discursivos analizados (Véanse las tablas 1 y 2). La imagen conceptual nos habla de un rico esquema teológico, moral, estético y científico. La llamada unidad de manifestación de sentido, del corpus discursivo analizado, establece intrincadas relaciones temáticas, semióticas y pragmáticas dirigidas a superar la problemática ambiental. El discurso ambiental proporciona esquemas y códigos mentales cuyos conceptos estructuran un rico relato y narrativa ambiental, anclado en la tradición judeocristiana, la filosofía clásica, la tradición teológica bizantina, un diálogo con la ciencia contemporánea y canales de acción pragmática. El carácter del discurso, objeto de investigación, es eminentemente ambiental. Se refleja la necesidad del hombre actual por comprender y darle soluciones a uno de los principales temas de la agenda mundial, como es la causa ambiental.

El discurso, como se ha comentado, tiene riquísimos referentes conceptuales que especifican un mundo de relaciones y campos de lo que constituye el fenómeno ambiental. En lo que respecta al modelo cristiano específicamente, este pretende, desde un ecumenismo serio, desde el diálogo inter-cultural y relacionamientos conceptuales, proporcionar las bases culturales, que el cristianismo apostólico, más allá de una pertenencia religiosa, le brinda al ser humano, como noción significativa para superar la crisis ambiental.

Hay una cadena de significados que el Patriarca Bartolomé construye, y que tienen que postularse como canales abiertos de significación ambiental anclados en la tradición de la iglesia Ortodoxa. El componente pragmático del discurso, que viene experimentando los rigores de la crisis ambiental, implica entender que los universos físicos, culturales y sociales de la humanidad, se ven necesariamente afectados por las cadenas de significados que se desarrollan de manera abierta, participativa y dialogal en el discurso del Patriarca. El discurso del Patriarca está ligado al universo cultural de la humanidad, su particularidad, centrada en la teología ortodoxa, establece un discurso ambiental en sintonía con los mejores aportes, que las narrativas científicas y religiosas, le pueden brindar a la humanidad 
para superar la grave crisis que vivimos.

Tabla 1. Terceridad/connotación profunda del principio trascendente

\begin{tabular}{|c|c|}
\hline \multicolumn{2}{|r|}{ Ámbito de lo sagrado / principio o plano trascendente } \\
\hline Categoría & Terceridad / connotación profunda \\
\hline $\begin{array}{c}\text { Dogma } \\
\text { referencial }\end{array}$ & $\begin{array}{l}\text { Su fundamento es la Verdad revelada a la Iglesia. Visión ampliada de } \\
\text { la realidad, cuya ontología central es de otro orden en relación con la } \\
\text { indagación científica, y cuya máxima es la búsqueda y la experiencia de } \\
\text { la Verdad. El dogma establece las dependencias de todas las cosas con } \\
\text { Dios. El mundo ha sido creado por Dios y la materia es radicalmente } \\
\text { diferente a Dios. }\end{array}$ \\
\hline $\begin{array}{l}\text { Concepción } \\
\text { ambiental } \\
\text { y visión de } \\
\text { mundo }\end{array}$ & $\begin{array}{l}\text { Deviene de la patrística griega y de la teología bizantina en diálogo con } \\
\text { los aportes contemporáneos de las ciencias ambientales. Se establece } \\
\text { una dimensión cósmica de la creación visible. La perspectiva ulterior se } \\
\text { entiende a la luz de un proceso de transfiguración del hombre mediante } \\
\text { la unión con Dios. }\end{array}$ \\
\hline $\begin{array}{l}\text { Particularidad } \\
\text { del dogma } \\
\text { referencial }\end{array}$ & $\begin{array}{l}\text { Se desarrolla con base en una teología experiencial vinculada a la } \\
\text { posibilidad real de la unión con Dios. Hay una valoración del mundo de } \\
\text { la naturaleza entendido en términos teológicos. Su racionalidad destaca } \\
\text { el lugar central del hombre en la naturaleza y su co-responsabilidad en } \\
\text { la restauración ambiental de ella. Anclado en la experiencia eclesial de } \\
\text { orden personal, comunitaria, ascética y eucarística. }\end{array}$ \\
\hline Patrística & $\begin{array}{l}\text { Destaca la patrística la posibilidad de trascender espiritualmente el } \\
\text { mundo material. El plano contemplativo es la acción fundamental del } \\
\text { hombre. La naturaleza no es objeto de adoración. Dios y naturaleza no } \\
\text { son lo mismo. No hay ninguna vinculación al panteísmo. La ciencia, } \\
\text { como el aporte de los pensadores clásicos, es indispensable para la } \\
\text { defensa de la visión cristiana. La problemática ambiental a la luz de } \\
\text { una comprensión cósmica que desborda las posibilidades del análisis } \\
\text { científico exclusivamente. }\end{array}$ \\
\hline $\begin{array}{c}\text { Respuestas } \\
\text { ortodoxas }\end{array}$ & $\begin{array}{l}\text { Los símbolos como expresión de la visión transfiguradora de toda la } \\
\text { narrativa ortodoxa. Creencia en la plenitud de vida de toda la creación. } \\
\text { La hagiografía ortodoxa está llena de ejemplos de una relación } \\
\text { precisamente tierna con la naturaleza y con los animales. Para el } \\
\text { pensamiento ortodoxo, el santo demuestra que es la persona en quien se } \\
\text { ha restaurado la debida relación entre las criaturas, que había quedado } \\
\text { perturbada por el pecado*. }\end{array}$ \\
\hline
\end{tabular}

* Felmy, K. (2002). Teología ortodoxa actual.Salamanca: Sígueme. 


\begin{tabular}{|c|c|}
\hline Sacralidad & $\begin{array}{l}\text { La propiedad primera del discurso que fija la creencia. Todo ha sido } \\
\text { creado por Dios. Todo tiene el sello de Dios. El mundo no opera como } \\
\text { una máquina. El mundo se comprende desde el misterio y desde una } \\
\text { concepción mística experiencial. Los sacramentos son los medios para } \\
\text { restaurar el cosmos. }\end{array}$ \\
\hline $\begin{array}{c}\text { Nuevo } \\
\text { Testamento }\end{array}$ & $\begin{array}{l}\text { Mensaje divino que establece las notas básicas de la nueva alianza, } \\
\text { cuyos contenidos enriquecen la lógica del Amor. Bases para nuevos } \\
\text { órdenes litúrgicos. } 2 \text { Tim 3,16-17: "Toda Escritura es inspirada por Dios, } \\
\text { y es útil para enseñar y para argumentar, para corregir y para educar en } \\
\text { la justicia, a fin de que el hombre de Dios sea perfecto y esté preparado } \\
\text { para hacer siempre el bien" }\end{array}$ \\
\hline $\begin{array}{c}\text { Antiguo } \\
\text { Testamento }\end{array}$ & $\begin{array}{l}\text { Mensaje divino que comunica y desarrolla el contenido básico y } \\
\text { sustancial de la salvación indicando un camino. Libro de vida que } \\
\text { contiene importantes indicaciones para construir o constituir el mundo } \\
\text { desde una claridad ligada al mensaje de Dios }\end{array}$ \\
\hline $\begin{array}{l}\text { Persona } \\
\text { humana }\end{array}$ & $\begin{array}{l}\text { Realidad central para el pensamiento católico. Dios como comunidad } \\
\text { de personas. La persona humana en relación con otros seres y con los } \\
\text { planos de la realidad. Vía y ontología relacional. Concepto de orden } \\
\text { pragmático en el pensamiento del Patriarca. Dios y la persona humana } \\
\text { como arquetipos de lo divino. La persona humana no es reducible del } \\
\text { todo a categorías discursivas del pensamiento humano. Igual sucede } \\
\text { con Dios. }\end{array}$ \\
\hline $\begin{array}{l}\text { Argumento } \\
\text { ontológico }\end{array}$ & $\begin{array}{l}\text { Dios es infinito, la creación es finita y ha sido creada por Dios. La } \\
\text { creación no es equivalente a Dios. Co-responsabilidad del hombre en la } \\
\text { preservación de la naturaleza. }\end{array}$ \\
\hline Iglesia & $\begin{array}{l}\text { Institución divina y humana que se origina de las intervenciones de } \\
\text { Dios en la realidad. Su misión la vincula a la historia de la salvación. } \\
\text { La creación de Dios debe ser uno de sus referentes misionales. Para } \\
\text { el patriarca, la misión de la Iglesia se entiende como unida al tema } \\
\text { ambiental. Lo que implica una evangelización ambiental, incorporada } \\
\text { como parte de la salvación en Cristo por parte del mundo y del hombre. } \\
\text { Libro de vida que contiene importantes indicaciones. } 2 \text { Pe 1,20-21: } \\
\text { "Pero, ante todo, tengan presente que ninguna profecía de la Escritura } \\
\text { puede interpretarse por cuenta propia; porque nunca profecía alguna } \\
\text { ha venido por voluntad humana, sino que hombres, movidos por el } \\
\text { Espíritu Santo, han hablado de parte de Dios". }\end{array}$ \\
\hline
\end{tabular}




\begin{tabular}{|c|l|}
\hline $\begin{array}{c}\text { Papel de la } \\
\text { religión }\end{array}$ & $\begin{array}{l}\text { Acción prototípica de orden religiosa que desborda el campo del } \\
\text { discurso aun cuando lo incluye. Las configuraciones religiosas están } \\
\text { insertas en circuitos de comunicación: los dioses, dios, el sacerdote, el } \\
\text { pueblo, la ofrenda, los elementos retóricos existentes en las oraciones }\end{array}$ \\
e invocaciones, la congregación**. Se destaca su valor como circuito \\
comunicativo de orden ambiental. Se advierte el riesgo de una \\
religiosidad cuya ornamentación dogmática pueda terminar destruyendo \\
el núcleo o kerigma del mensaje y práctica del cristianismo. El correlato \\
y efectos de la anterior condición se expresan en la división profunda \\
que vive el cristianismo dada la presencia de iglesias históricas, \\
nacionales, étnicas y totalitarias.
\end{tabular}

\section{FUENTE: AUTOR}

**: Yelle, R. (2012). Semiotics of religion, Signs of the sacred in History. London: Bloomsbury.

\section{Huellas de sentido ambiental}

En la semiosis ortodoxa derivada del pensamiento ambiental del patriarca, los resultados analíticos del trabajo, analizados el 100\% de los documentos producidos en los últimos 26 años, afirman que el signo ambiental se construye con base en la triada Dios-HombreTierra. Contrasta esta ordenación lógica, en lo referido a los principales documentos del magisterio de la Iglesia Católica, donde el signo ambiental se expresa consecutivamente mediante los sustantivos Social- Dios-Vida. Estamos hablando de los principales sustantivos que emergen del sistema de producción discursivo articulado en el uso de unos trece mil términos. Entonces una de esas diferencias radicales, tiene que ver precisamente con el anclaje patrístico del pensamiento ambiental usado por el Patriarca. Los usos patrísticos, en el marco de un diálogo contemporáneo, sostenido por el Patriarca en los espacios académicos, políticos y sociales más diversos, 
se motivan como la expresión de una experiencia de orden ligada a los planteamientos de punta y enfoques cosmopolíticos contemporáneos más novedosos. Es decir, el discurso del Patriarca como líder religioso durante los últimos 26 años, refiere un universo discursivo que establece canales de comunicación y significación, que connotan la riqueza del modo de producción discursivo del pensamiento ambiental católico y ortodoxo, en su referencia a las redes discursivas y sus relacionamientos que han sido esquematizadas en las tablas. En ese orden de ideas, los Padres de la Iglesia, tienen mucho que aportar al mundo de hoy. La labor evangélica de los Padres apostólicos - directos discípulos de los apóstoles, apologistas, santos y misioneros cristianos de los primeros mil años de la Iglesia - es esencial para la vida y la fe de todos los cristianos que han vivido en épocas y tiempos posteriores a esos periodos de gloria, martirio y de acción providencial de la acción del Espíritu Santo en la historia. Lo que denominamos como patrística, expresa la narrativa clásica del cristianismo.

El análisis se realizó sobre los planos del contenido principalmente. Ahora, por el rol del actor productor del mensaje, el plano de la expresión es también de vital importancia; tanto los gestos, signos, espacios académicos y religiosos, como el papel protagónico que ha ganado el Patriarca en los últimos años, le confieren a sus palabras y expresiones, un valor correlativo al que tiene el estudio del plano del contenido. Hay una compleja red de elementos constitutivos del plano de la expresión que deben ser tenidos en cuenta: los campos y auditorios visitados por el Patriarca, sus atuendos, las ceremonias religiosas que atiende y/o preside, las redes de comunicación donde fluyen sus palabras, ideas, conceptos y argumentos, los textos académicos producidos en los seminarios organizados, las modificaciones, impactos y apropiaciones realizadas por científicos, políticos y público en general que participa en las arenas donde circula la temática ambiental que se genera. Nuestra lectura, siguiendo la tradición lingüística, postula hipotéticamente que la unidad mínima, tanto del plano de la expresión como del contenido, estaría mediado por la relación cósmica fijada por los siguientes signos o cadenas de significación: Dios-persona humana-territorio. Estas cadenas de significación tienen que reconstruirse como unidades de sentido y como unidades de sentido operativo. La unidad de sentido, dadas las prácticas culturales de carácter secular, han erosionado el sentido de lo ambiental, dada la evidencia histórica sobre la fragmentación del cristianismo; por lo tanto, sino hay una clara continuidad entre el sentido marcado por la tradición, el sentido 
operativo se desplegará fragmentariamente. Entonces lo que el Patriarca ha realizado, ha sido una organización teológica y pastoral del plano del sentido, cuyo correlato es de orden dialógico con las principales corrientes de la ciencia ambiental contemporánea. El rasgo elemental, lo hemos definido a la luz de la noción de pensamiento nuclear. Es la unidad mínima se sentido que específica la terceridad cristiana en materia ambiental. El sentido ambiental, apelando al criterio emic, se entiende como dirección y despliegue de la terceridad cristiana; esta condición del conocimiento se constituye en el canal comunicativo para la construcción de un gran argumento ambiental, postulado con base en una ontología mitopoética que se articula paradigmáticamente con la realización del reino de Dios en la vida del creyente, en los grupos humanos y en el mundo (Véanse las tablas 2 y 3 ).

Tabla 2. Terceridad/connotación profunda de las estructuras narrativas

\begin{tabular}{|c|l|}
\hline \multicolumn{2}{|c|}{ Ámbito de lo profano/empiricidad } \\
\hline Categoría & \multicolumn{1}{|c|}{ Terceridad / connotación profunda } \\
\hline $\begin{array}{c}\text { Remedios y } \\
\text { soluciones }\end{array}$ & $\begin{array}{l}\text { Importante énfasis en la experiencia y anclaje de la liturgia. El mensaje } \\
\text { mantiene continuidad con los aportes de los apóstoles, mártires y santos. } \\
\text { La Iglesia ha hecho uso de los símbolos naturales para enriquecer } \\
\text { el espacio de adoración por excelencia de los creyentes. Tradición } \\
\text { creadora de vida, que nace del agua y del espíritu (Juan 3.5), ordenada } \\
\text { a la santificación o deificación de los creyentes y operando desde la } \\
\text { conversión o cambio de mente (metanoia). Se está hablando de remedios } \\
\text { espirituales, que implican una re-consideración de nuestra concepción } \\
\text { de mundo. Esos remedios tienen que contribuir a superar el egó́smo } \\
\text { y la ipseidad humana, estados que se traducen en la incapacidad de } \\
\text { mirar hacia el orden creado de la naturaleza. Debe buscarse restablecer } \\
\text { el cosmos sagrado desde el celo, el amor y la intimidad de la teología } \\
\text { sacramental. }\end{array}$ \\
\hline $\begin{array}{c}\text { Denuncia, } \\
\text { conflicto y } \\
\text { crítica }\end{array}$ & $\begin{array}{l}\text { Severa crítica al excesivo materialismo que orienta las acciones humanas } \\
\text { en el plano de las relaciones con la realidad. Los efectos de esas fuerzas } \\
\text { se manifiestan en la disminución de la dignidad de la persona y en el } \\
\text { rechazo de las realidades divinas. Las acciones destructivas del hombre } \\
\text { hacia la naturaleza tienen que comprenderse como acciones contra la } \\
\text { realidad increada de Dios. Reconoce las escalas locales, regionales y } \\
\text { globales de la problemática ambiental. }\end{array}$ \\
\hline
\end{tabular}




\begin{tabular}{|c|c|}
\hline $\begin{array}{l}\text { Campo } \\
\text { académico }\end{array}$ & $\begin{array}{l}\text { Un importante reconocimiento del mundo de la ciencia y la academia y } \\
\text { de sus aportes a la comprensión y solución de la problemática ambiental. } \\
\text { Espacio profano privilegiado en el discurso ambiental del Patriarca. }\end{array}$ \\
\hline $\begin{array}{l}\text { Canales de } \\
\text { diálogo }\end{array}$ & $\begin{array}{l}\text { Referencia al diálogo inter-cultural. Se reconocen respetuosos } \\
\text { pronunciamientos hacia los católicos romanos, el mundo protestante } \\
\text { y otras religiones no cristianas. Realiza lecturas de comunicados } \\
\text { enviados por el Papa Juan Pablo II y el Papa Benedicto XVI en los } \\
\text { eventos organizados por el patriarcado. El diálogo se entiende como } \\
\text { una oportunidad única para explorar las profundidades de la riqueza } \\
\text { teológica y científica. Es un canal para engrandecer la belleza de la } \\
\text { creación de Dios. }\end{array}$ \\
\hline Causalidad & $\begin{array}{l}\text { Factor marcado por dimensiones ontológicas y físicas. Referencia tanto } \\
\text { a planos empíricos explicativos de los problemas ambientales, como a } \\
\text { planos ontológicos que hablan de los profundos desarreglos que ocurren } \\
\text { en el corazón humano. La raíz de los problemas ambientales tiene que } \\
\text { ver con la renuncia y abandono de la virtud y de la falta de piedad } \\
\text { hacia el mundo de la naturaleza. Se ha impuesto un eje de acciones } \\
\text { centradas en el poder, mediante el cual el hombre ha querido divinizarse } \\
\text { a sí mismo. }\end{array}$ \\
\hline $\begin{array}{l}\text { Problemas } \\
\text { prioritarios }\end{array}$ & $\begin{array}{l}\text { Se reconoce la dimensión global de la problemática ambiental. Esta } \\
\text { tiene características trágicas y se expresa de manera grave en todos los } \\
\text { grandes ecosistemas y biomas del mundo. Se habla de contaminación } \\
\text { química, cambio climático, contaminación de ríos y mares, pérdida de } \\
\text { la biodiversidad, deterioro de los mares por acción de las petroleras. Se } \\
\text { reconoce que el problema está bien documentado. Las dimensiones de } \\
\text { la crisis ambiental son amenazantes y apocalípticas. }\end{array}$ \\
\hline $\begin{array}{l}\text { Argumento } \\
\text { ciencias } \\
\text { naturales }\end{array}$ & $\begin{array}{l}\text { Un diálogo y reconocimiento de los aportes y desarrollos de las ciencias } \\
\text { de la Tierra. Las consecuencias del deterioro ambiental del planeta } \\
\text { se ven como catastróficas para millones de personas. La mayoría de } \\
\text { los espacios sociales frecuentados por el Patriarca refieren un campo } \\
\text { académico marcado por la presencia y aportes de las ciencias naturales. }\end{array}$ \\
\hline Territorialidad & $\begin{array}{l}\text { Los simposios científicos organizados se enmarcan en temas } \\
\text { que directamente abordan los problemas físicos, ecosistémicos y } \\
\text { ambientales. La referencia es importante dado el impacto del modelo } \\
\text { económico dominante sobre territorios y ecosistemas. }\end{array}$ \\
\hline $\begin{array}{l}\text { Principios } \\
\text { morales y } \\
\text { éticos }\end{array}$ & $\begin{array}{l}\text { La intertextualidad deriva de los principios sagrados fundamentales del } \\
\text { cristianismo ortodoxo. El ethos que proclama la dignidad del hombre, } \\
\text { partiendo de su imagen y semejanza con Dios, debería proclamar la } \\
\text { misma dignidad de la naturaleza creada por Dios. Eje el mandamiento } \\
\text { del Amor y la misericordia derivado del mandato evangélico de Jesús. }\end{array}$ \\
\hline $\begin{array}{l}\text { Acción } \\
\text { ambiental }\end{array}$ & $\begin{array}{l}\text { Medidas orientadas a detener las causas de la crisis ambiental y a } \\
\text { mejorar la calidad de vida del ser humano. }\end{array}$ \\
\hline
\end{tabular}




\begin{tabular}{|c|l|}
\hline Pragmatismo & $\begin{array}{l}\text { Acción y experiencia misionera de llevar la buena nueva del evangelio } \\
\text { a todos los pueblos. El mensaje ambiental hace parte del evangelio. } \\
\text { Reconoce que no son suficientes las denuncias verbales. Se requiere la } \\
\text { movilización. El mensaje de la Iglesia no se reduce simplemente a un } \\
\text { tema espiritual, tiene que incluir dimensiones ambientales. }\end{array}$ \\
\hline $\begin{array}{c}\text { Campo } \\
\text { político }\end{array}$ & $\begin{array}{l}\text { Muchos de los pronunciamientos del Patriarca se han realizado en } \\
\text { importantes escenarios políticos: el parlamento de la Unión Europea, } \\
\text { parlamentos, diálogos con los primeros ministros y presidentes del } \\
\text { mundo. }\end{array}$ \\
\hline $\begin{array}{c}\text { Anclaje } \\
\text { filosofía } \\
\text { clásica }\end{array}$ & $\begin{array}{l}\text { Relaciones con el pensamiento griego: Heródoto, Homero, Aristóteles, } \\
\text { Platón. }\end{array}$ \\
\hline $\begin{array}{c}\text { Relaciona- } \\
\text { miento }\end{array}$ & $\begin{array}{l}\text { La pastoral y teología del Patriarca es de orden relacional: está en } \\
\text { capacidad de dialogar y establecer vínculos con la filosofía, la ciencia } \\
\text { contemporánea, otras religiones y otras confesiones cristianas. }\end{array}$ \\
\hline $\begin{array}{c}\text { Cambio } \\
\text { climático }\end{array}$ & $\begin{array}{l}\text { Una de las expresiones más discutidas de la problemática ambiental por } \\
\text { parte del patriarca (Véase: Autor, 2014). }\end{array}$ \\
\hline
\end{tabular}

FUENTE: AUTOR.

\section{Discusión}

Los estudios ambientales referidos al tema de la percepción, interés aparentemente nuevo para la ecología y otras ciencias ambientales, han sido un campo de estudio desarrollado por un importante movimiento colectivo al interior de la antropología, que generó procesos de investigación que datan de 1956 y que mantuvieron su auge hasta 1969. Es decir, estamos en el marco de una tradición de investigación que tiene cincuenta años. El tema de la percepción y del significado otorgado a la naturaleza por otras culturas, ha sido abordado por la antropología cognitiva, la etnosemántica, la etnociencia, la nueva etnografía, y el análisis componencial. Estas subdisciplinas antropológicas han establecido contacto con los enfoques propios de la etnobotánica y la etnoecología. La base lingüística y antropológica de todos estos enfoques fue central, sin embargo, otras ramas del saber cómo la filosofía fenomenológica, la psicología gestáltica y el psicoanálisis, también generaron influencias en un amplio número de antropólogos. Para antropólogos como Carlos Reynoso el movimiento al que se alude, tuvo su auge y es de cierta manera una postura investigativa que se asume como superada y que sin embargo, como lo demuestra este 
trabajo, tiene importantes desarrollos que pueden contribuir a la solución y esclarecimiento de problemas políticamente relevantes para el mundo contemporáneo ${ }^{1}$.

Las combinaciones temáticas que plantea la narrativa analizada, ya sea dentro de un modelo basado en el esquema del significante y significado (diádico) o apoyado en una relación triádica que mira el signo, el objeto y el interpretante, pueden establecer series de sentido que tienen que pasar a ser vividas por las personas, los grupos, colectividades y naciones desde el plano de sentido ambiental.

Dentro del paradigma ambiental, se denota poco desarrollo del aporte de las ciencias sociales. El factor explicativo preponderante es el modelo de las ciencias naturales, en el que participa su poder descriptivo y su fuerza en lo relativo a captar la causalidad de la crisis ambiental. Las categorías que hemos agrupado en dos órdenes clasificatorios de la realidad: el plano de lo trascendente/sagrado y el plano de lo inmanente/ profano, están connotando la riqueza del universo discursivo del cristianismo ortodoxo en su capacidad de reconocer e interactuar con un universo perceptivo caracerizado por la rápida transformación del mundo contemporáneo en sus referencias líquidas, secularistas, relativistas y de cansancio espiritual. El correlato ambiental de este universo, determina y es a su vez determinado, por las categorías de la memoria semántica, contenida en los modelos mentales manejados con el Patriarca y por la tradición patrística y bizantina que él operativiza desde el lenguaje y el ritual. Los esquemas y estructuras narrativas analizados y presentados tienen un "aire de familia", que los diferencia de manera clara, de la narrativa ambiental que se encontrará en los documentos magisteriales de la tradición católica romana ${ }^{2}$.

El conjunto de significaciones que se han encontrado definen un estilo propio y particular, marcado por una teología mística de orden experiencial principalmente. Las capas del discurso que hemos presentado, expresan una jerarquía multifoliada de significaciones, cuyo fin busca la realización de la unión con Dios en la vida del creyente y en la posibilidad de que los no-creyentes se incorporen al pueblo de seguidores de Jesús

1 Reynoso, C. (1998). Corrientes en antropología contemporánea. Buenos Aires: Editorial Biblos, 11.

2 Papa Francisco. (2015). Carta Encíclica Laudato Sí. Sobre el cuidado de la casa Común. Quito: Editorial Paulinas. 
Cristo. Los conjuntos de significación mencionados, establecen que el mundo natural, como expresión de la creación de Dios, es un componente de la realidad divina que los seres humanos tenemos que aprender a respetar y a amar. La narrativa que se ha estudiado hace parte de una historia y una cultura cristiana que tiene que ser vivida y explorada profundamente.

\section{Conclusiones}

La crisis ambiental contemporánea implica abrir espacios para la consolidación de un paradigma ambiental que busque integrar los conocimientos de la ciencia y tenga la posibilidad de valorar las formas tradicionales, religiosas y espirituales de ver la realidad. La narrativa observada y analizada nos permite ver la importancia del reconocimiento de la articulación entre Verdades religiosas y verdades científicas. La expresión de la estructura narrativa analizada se expresa desde una ontología diferente a la de la ciencia. Se puede afirmar que ambas narrativas son complementarias y enriquecen nuestra comprensión de la realidad. La narrativa religiosa establece unos contenidos y sentidos que no constituyen la base central de la indagación científica, pero sí expande los sentidos y el horizonte de las verdades científicas en su capacidad de aprensión de lo real y la realidad La superación de la problemática ambiental implica pensar y repensar la articulación de los fenómenos socioculturales y su relación interactiva con realidades ecosistémicas, biológicas y cósmicas. Los estudios sobre percepción del ambiente y sus concepciones implican el descubrimiento de las pautas de ver, pensar y de actuar en la realidad que hacen parte del conocimiento y de la herencia social de los sistemas culturales que nos brindan en el marco de sus respuestas adaptativas (inadaptativas) muchas claves, signos y puentes para la superación de la problemática ambiental que viven los sistemas culturales contemporáneos.

La narratividad estudiada en su referencia a la crisis ambiental y a los aportes de la teología ortodoxa para la superación de la misma, refleja la experiencia de orden de connotaciones cosmo-políticas que se derivan de la concepción griega y cristiana que veían en la naturaleza una gran teofanía que permanentemente recordaba que la naturaleza era la expresión visible de la esencia-energía invisible de un Dios creador. En el pensamiento ortodoxo contemporáneo, expresado en la voz narrativa del Bartolomé, Patriarca Ecuménico de Constantinopla se mantiene dicha continuidad narrativa. La naturaleza, al igual que como sucede en las cosmovisiones de muchos pueblos tradicionales, es fuente de sabiduría. 
En la visión cristiana, la naturaleza es un canal y medio, cuya iconicidad, manifiesta a Dios en toda su gloria y sabiduría. Ella se expresa como el gran referente inspirador de la antigua, rica y evocadora noción de liturgia cósmica de la que nos hablaba san Máximo el Confesor en el siglo octavo de la era cristiana.

\section{BIBLIOGRAFÍA}

BARTHES, R. (1990). La aventura semiológica. Barcelona: Paidós.

BATESON, G. (1982) Una unidad sagrada: pasos ulteriores hacia una ecología de la mente. Barcelona: Gedisa,

BATESON, G. (1971). Pasos hacia una ecología de la mente.

Buenos Aires: Planeta,

-, (2016). "El signo paisaje cultural desde los horizontes de la antropología semiótica". AIBR, Revista de Antropología Iberoamericana,

Madrid: AIBR, 11 (01).

-, $\left(2015^{\mathrm{a}}\right)$. "Categorías y códigos discursivos del cristianismo en su proceso de adaptación humana a la crisis ambiental". En: La sacralidad de la vida en una Tierra habitable para todos. Universidad Popular del Estado de Puebla-México.

-, (2015b). Christianity and sustainable development: the case of Ethiopia. https://youtu.be/OA5FDCopjRs

---------, (2015c). Ethiopia: sacred land.

https://youtu.be/xqMr2ce0FO0

--------, (2015d). Ethiopia sacred land II.

https://youtu.be/xqMr2ce0FO0

--------, (2015e). AbuneMathias: Patriarch of Ethiopia.

https://youtu.be/CNdr8zHbi7I

---------, (2014). "Cambio climático y su apropiación en la pastoral católica-

ortodoxa. El magisterio de Su Santidad Bartolomé, Patriarca Ecuménico de Constantinopla”. En: Diálogo Ecuménico. Universidad Pontificia de Salamanca: Centro de Estudios Orientales y Ecuménicos "Juan XXIII", Tomo 49, №. 154-155, págs. 79-96.

, (2008). "Crisis ambiental y cristianismo". Teología y vida. Pontificia Universidad Católica de Chile-Facultad de Teología, vol. 49, no. 4, pp. 771-797.

, (2007). "Los silenciamientos de la ciencia ambiental. Una reflexión crítica sobre estructuras de opresión”, En: Nómadas. Revista Crítica de Ciencias Sociales y Jurídicas.16, Madrid: Universidad Complutense. Julio-Diciembre. 
---------, (2006). “Vida, ambiente y percepción. Breve aproximación a los modelos de interpretación ambiental". En: Revista Ideas ambientales. Edición Número 2. Manizales: Universidad Nacional de Colombia.

----------, (2002). Antropología y ambiente: enfoques para una comprensión de la relación ecosistema-cultura. Bogotá: Javergraf.

DUCH, L. (1998). Mito, interpretación y cultura, Barcelona: Herder.

ECO, H. (1996). Seis paseos por los bosques narrativos. Barcelona: Lumen.

FELMY, K. (2002). Teología ortodoxa actual. Salamanca: Sígueme.

FLORENSKI, P. (2010). La columna y el fundamento de la Verdad. Salamanca: Ediciones Sígueme.

GREIMAS, A.J. (1976). Semántica estructural, Investigación metodológica. Madrid: Gredos.

INGOLD, T. (2000). Essays in livelihood and skill. London: Routledge, LOSSKY, V. (1982). Teología mística de la Iglesia de oriente. Barcelona: Herder. LEVI, STRAUSS, C. (1971). Mitológicas. Méjico: Fondo de cultura económica, LUHMANN, N. (2007). La religión de la sociedad. Barcelona: Trotta.

NESTERUK, A. (2003). Light from the East.Theology, Science, and the Eastern Orthodox Tradition. Minneapolis: Fortress press.

SAUSSURE, F. (2005). Curso de lingüistica general. Buenos Aires: Losada.

STRAND, T. (2013). Peirce's Rhetorical Turn. Conceptualizing education as semiosis. Educational Philosophy and Theory.Vol. 45, No. 1.

PAPA FRANCISCO. (2015). Carta Encíclica Laudato Sí. Sobre el cuidado de la casa Común. Quito: Editorial Paulinas.

PEIRCE, C. (1978). Lecciones sobre el pragmatismo. Buenos Aires: Editorial Aguilar.

PERLS, F. (1982). Terapia Gestalt: teoría y práctica. Méjico: Concepto.

REYNOSO, CARLOS. (1998). Corrientes en antropología contemporánea. Buenos Aires: Editorial Biblos.

VERÓN, E. (1987). La semiosis social. Fragmentos de una teoría de la discursividad. Barcelona: Gedisa.

YELLE, R. (2012). Semiotics of religion, Signs of the sacred in History. London: Bloomsbury. 